\title{
Effects of Nalbuphine and Fentanyl as Adjuvants to (0.5 \%) Isobaric Levobupivacaine in Subarachnoid Block for Elective Transurethral Endoscopic Surgeries
}

\author{
Dinesh G. ${ }^{1}$, Shilpa G.B. ${ }^{2}$, Greeshma N. Murdeshwar ${ }^{3}$ \\ 1,2, 3 Department of Anaesthesiology, Mysore Medical College \\ and Research Institute, Mysore, Karnataka, India.
}

\section{ABSTRACT}

\section{BACKGROUND}

Isobaric levobupivacaine has minimal effect on positional variation of sensory and motor blockade given intrathecally. Also, it has lesser cardiotoxic and neurotoxic effects. Present study was done to compare efficacy, analgesia haemodynamic effects and any adverse effects after spinal anaesthesia with isobaric levobupivacaine with nalbuphine and fentanyl as adjuvants in transurethral endoscopic surgeries.

\section{METHODS}

60 male adult patients of American Society of Anaesthesiologists (ASA class I-III) of age group 40 - 80 years were randomized into 2 groups $(n=30)$ in this prospective, double blinded study. $10 \mathrm{mg}$ of $0.5 \%$ levobupivacaine with $25 \mu \mathrm{g}$ fentanyl in group LF and $10 \mathrm{mg}$ of $0.5 \%$ levobupivacaine with $0.8 \mathrm{mg}$ nalbuphine in group LN. Parameters assessed were sensory and motor blockade characteristics and hemodynamic variables in both the groups. Adverse effects were recorded if any.

\section{RESULTS}

Onset of sensory and motor blockade were significantly faster in group LF compared to group LN. In both the groups, time for two segment regression was comparable. Statistically significant prolonged analgesic duration was noticed in group with nalbuphine than fentanyl as adjuvant to isobaric levobupivacaine. Difference in haemodynamic variation was not significant in both the groups.

\section{CONCLUSIONS}

Intrathecal nalbuphine $0.8 \mathrm{mg}$ as an adjuvant with isobaric levobupivacaine $0.5 \%$ $10 \mathrm{mg}$ is as efficacious as fentanyl $25 \mu \mathrm{g}$ in transurethral endoscopic surgeries in elderly population with better hemodynamic stability.

\section{KEY WORDS}

Levobupivacaine; Fentanyl; Nalbuphine; Spinal anaesthesia.
Corresponding Author: Dr. Greeshma N. Murdeshwar, Flat No. 2b, Pinewood Park Apartment, Ambedkar Road, Near RTO Circle, Laxmipuram, Mysuru-570004, Karnataka, India.

E-mail:

greeshma.murdeshwar@gmail.com

DOI: $10.14260 /$ jemds/2021/686

How to Cite This Article:

Dinesh G, Shilpa GB, Murdeshwar GN. Effects of nalbuphine and fentanyl as adjuvants to $(0.5 \%)$ isobaric levobupivacaine in subarachnoid block for elective transurethral endoscopic surgeries. J Evolution Med Dent Sci 2021;10(38):3380-3386, DOI: 10.14260/jemds/2021/686

Submission 26-07-2021,

Peer Review 10-09-2021,

Acceptance 13-09-2021,

Published 20-09-2021.

Copyright (C) 2021 Dinesh G. et al. This is an open access article distributed under Creative Commons Attribution License [Attribution 4.0 International (CC BY 4.0)] 


\section{BACKGROUND}

Neuraxial anaesthesia techniques for transurethral endoscopic surgeries are cost effective with post-operative analgesia and early patient mobilization facilitating shorter hospital stay. ${ }^{1,2}$ Spinal anaesthesia provides major advantages over general anaesthesia, such as reduced operative blood loss and by allowing intraoperative monitoring of patient's mental status enables early detection of over hydration, bladder perforation, (trans urethral resection of prostate) TURP syndrome and it lowers incidence of deep vein thrombosis. ${ }^{3,4}$

Most patients undergoing TURP are elderly with coexisting cardiopulmonary diseases. Therefore, it is essential to reduce adverse cardiopulmonary effects by limiting level of spinal block. ${ }^{5}$ Also in elderly space identification might be difficult, increased sensitivity to the drugs, positioning may be difficult due to calcified ligaments and there is decreased cerebrospinal fluid (CSF) volume. The complications due to delayed immobilization can be prevented by using short acting spinal anaesthesia. If motor block was less intense, the recovery and mobilization of the patient could be faster which can be attained by using short acting or low doses of local anaesthetics. ${ }^{3,4}$

Lithotomy positioning increases venous return. Decompensated patients are at risk of congestive cardiac failures. It can also decrease lung capacities as there is cephalad shift of the viscera. The normal lordotic curve of lumbar spine is lost which can aggravate lower back pain. Also, there are chances of nerve injuries.

Local anaesthetic suitable for spinal anaesthesia should provide effective anaesthesia and analgesia intraoperatively and should have no side effects. ${ }^{6,7}$ Most commonly used local anaesthetic is hyperbaric bupivacaine in regional anaesthesia. It is a racemic mixture of two enantiomers, levobupivacaine, $\mathrm{S}$ $(-)$ isomer and dexrobupivacaine, $\mathrm{R}(+)$ isomer. Levobupivacaine, the S (-) enantiomer of racemic bupivacaine has relative potency ratio of 0.97 compared to bupivacaine. Due to its lower affinity for cardiac sodium channels, levobupivacaine has less cardiotoxic potential compared to bupivacaine. ${ }^{8}$ Hence. its popular for central neuraxial blocks. The major advantage of isobaric anaesthetic is that level of block is unaffected by position of the patient which is useful in elderly patients undergoing TURP where level of T10 or below is required. 9

To improve the block characteristics of intrathecally administered local anaesthetic with dose reduction, addition of adjuvant is necessary. Fentanyl, an opioid agonist acts on mu receptors. Nalbuphine is a semi synthetic opioid which acts as kappa receptor agonist and mu receptor antagonist. It has potential to provide good intra and post-operative analgesia with the absence of mu receptor side effects. Hence, relatively lower respiratory depressant effect and abuse potential. ${ }^{10}$ There is no documented report of neurotoxicity with nalbuphine. ${ }^{11}$ Being recently introduced in India, it is studied as an adjuvant in different doses to hyperbaric bupivacaine in central neuraxial techniques by intrathecal, epidural and caudal routes and in peripheral nerve plexus blocks. However, there are very few studies of nalbuphine as an adjuvant to isobaric levobupivacaine. Hence, we have conducted the present study to assess and compare clinical efficacy of nalbuphine $0.8 \mathrm{mg}$ as an adjuvant to $10 \mathrm{mg}$ isobaric levobupivacaine with fentanyl 25 micrograms as an adjuvant to $10 \mathrm{mg}$ isobaric levobupivacaine combination in elective transurethral endoscopic surgeries

\section{Objective of Study}

To assess sensory and motor blockade characteristics of 0.8 mg nalbuphine verses fentanyl $25 \mu \mathrm{g}$ as adjuvants to $10 \mathrm{mg}$ isobaric levobupivacaine and compare post-operative analgesic duration in transurethral endoscopic surgeries. Secondary objectives are to evaluate associated intra operative hemodynamic conditions and to observe if any adverse effects in both the groups.

\section{METHODS}

Institutional ethical committee clearance was taken for this prospective, randomised, double blinded study. The study was conducted from November 2018 to July 2020. Sixty subjects aged between 40 to 80 years belonging to ASA Class I-III posted for elective endoscopic urological procedures were selected for the study. Informed consent was taken from all the study participants. Nonprobability convenient sampling technique was adopted to select the sample. The study population were divided randomly by shuffled sealed opaque envelope technique into 2 groups with 30 subjects in each group $(n=30)$.

- Group LF: received $10 \mathrm{mg}(2 \mathrm{ml})$ of $0.5 \%$ isobaric levobupivacaine with $25 \mu \mathrm{g}$ fentanyl.

- Group LN: received $10 \mathrm{mg}(2 \mathrm{ml})$ of $0.5 \%$ isobaric levobupivacaine with $0.8 \mathrm{mg}$ nalbuphine.

Patients were excluded if there were spinal deformities, local skin infection, coagulation disorders, impaired renal or liver functions, history of allergy to the study drugs, opioid dependence, and patients with body mass index $>30 \mathrm{~kg} / \mathrm{m}^{2}$.

Preoperative assessment with required investigations was done for each patient and were optimized. Patients were instructed to fast for solids for 6 hours and clear liquid for 2 hours. Intravenous (IV) line was taken and patients were preloaded with Ringer lactate $500 \mathrm{ml}$ half an hour before anaesthesia.

Monitoring was done using multiparameter monitor having electrocardiography (ECG), non-invasive blood pressure (NIBP) and arterial pulse saturation (SPO2). Patients were placed in sitting position with table kept flat. With aseptic precautions, lumbar puncture was performed at the level of L3-L4 interspace through a midline approach using 25 G Quincke's spinal needle and study drug combination was injected after confirming by free flow of CSF. The test drugs either $10 \mathrm{mg}(2 \mathrm{ml})$ of $0.5 \%$ of isobaric levobupivacaine with $25 \mu \mathrm{g}$ fentanyl or $10 \mathrm{mg}(2 \mathrm{ml})$ of $0.5 \%$ of isobaric levobupivacaine with $0.8 \mathrm{mg}$ nalbuphine was loaded in a $5 \mathrm{ml}$ syringe just before spinal anaesthesia, by a senior anaesthesiologist who was also involved in randomization of patient and was not involved with other parts of the study. Spinal anaesthesia for all subjects in the study was given by the primary investigator who was the observer too. Thus, both the observer and the subjects were blinded to the study drugs. Subjects were made to lie down in the supine posture immediately. 


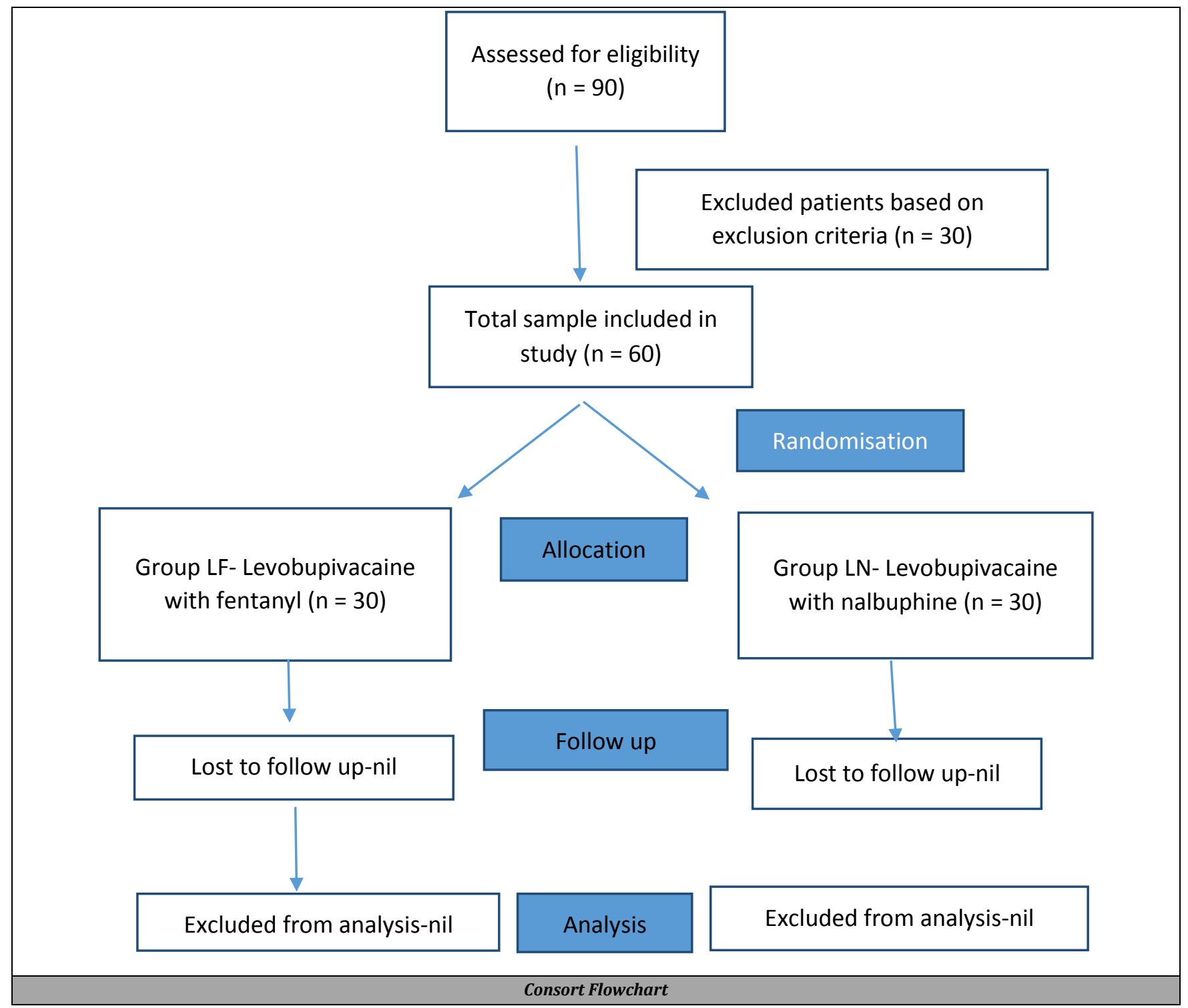

The following parameters were noted. Onset of sensory blockade (interval between complete drug injection till loss of pin prick at T10 level) and motor blockade (interval between complete drug injection till patient develops Bromage-1 motor block). Pinprick was used to assess sensory blockade attained with 27G hypodermic needle at the intervals 2 mins and 5 mins within first 30 mins after the spinal injection; then at $15 \mathrm{~min}$ intervals between 30 and $120 \mathrm{mins}$, and thereafter at 30 min intervals until complete recovery.

Maximum level of sensory (interval between complete drug injection to the maximum sensory blockade attained) and maximum motor blockade attained (interval between complete drug injection to the maximum motor blockade attained) were noted. Quality of motor blockade was assessed by modified Bromage scale.

Bromage 0 - subject is able to move the hip, knee and ankle; Bromage 1- subject is able to flex his knee and ankle; Bromage 2 - subject is able to flex his ankle; Bromage 3subject is able to move his toes and Bromage 4 - complete paralysis.

Also, time for two segments sensory regression (time to regress maximum sensory level by 2 segments), total duration of analgesia (time to first rescue analgesia which was injection of diclofenac $75 \mathrm{mg}$ in our study) and side effects were noted.

All subjects were monitored intra and perioperatively till complete sensory and motor recovery with multi parameter monitors.

Hypotension was considered if systolic blood pressure (SBP) drops more than $20 \%$ below baseline or SBP falls less than $90 \mathrm{~mm}$ of $\mathrm{Hg}$, and it would be treated with fluids rush or vasopressors (IV mephentermine $3 \mathrm{mg}$ bolus). Bradycardia was considered if heart rate (HR) was less than 60 beats/minute and treated with IV atropine $0.6 \mathrm{mg}$.

Subjects were monitored for occurrence of adverse events like nausea, vomiting, respiratory depression or oxygen desaturation, hypotension, bradycardia or TURP syndrome.

\section{Sample Size Calculation}

Based on our pilot study, a difference of 60 minutes in the duration of sensory and motor block (modified Bromage score $>1$ ) was taken to be clinically significant. For group comparison based on a simple stratified two sample $95 \% \mathrm{t}$ based confidence interval with $80 \%$ power, an estimated 26 
patients per group were necessary. For drop out compensation, a total of 60 patients were taken.

\section{Statistical Analysis}

Data was analyzed using Statistical Package for Social Sciences (SPSS 22 version software). Categorical data was represented as frequencies and proportions. Qualitative data statistical significance was analysed with chi-square test or Fischer's exact test. Continuous data was represented as mean and standard deviation. Quantitative variables statistical significance was analysed with independent t-test. $P$ value $<0.05$ was considered as statistically significant.

\section{RESULTS}

\begin{tabular}{|c|c|c|c|c|c|}
\hline Sl. No. & \multicolumn{2}{|c|}{ Parameters } & Group - LF & Group - LN & P Value \\
\hline 1. & \multicolumn{2}{|r|}{ Age } & $68.57 \pm 7.17$ & $67.83 \pm 5.85$ & 0.66 \\
\hline \multirow[t]{2}{*}{2.} & ASA & II & $16(53.3 \%)$ & 17 (56.7 \%) & \multirow{2}{*}{0.759} \\
\hline & & III & $14(46.7 \%)$ & $13(43.3 \%)$ & \\
\hline \multirow[t]{4}{*}{3.} & $\begin{array}{c}\text { Co- } \\
\text { morbidities }\end{array}$ & Diabetes mellitus & $3(10 \%)$ & $4(13.3 \%)$ & \multirow{4}{*}{0.942} \\
\hline & & Hypertension & $7(23.3 \%)$ & $6(20 \%)$ & \\
\hline & & Respiratory disease & $4(13.3 \%)$ & $3(10 \%)$ & \\
\hline & & None & $16(53.3 \%)$ & $17(56.7 \%)$ & \\
\hline 4. & Dura & on of surgery & $49.97 \pm 10.63$ & $51.40 \pm 10.35$ & 0.599 \\
\hline
\end{tabular}

Both the groups were comparable with respect to demographic characteristics, associated comorbidities and duration of surgery.

\begin{tabular}{|c|c|c|c|c|c|}
\hline \multirow[b]{3}{*}{$\begin{array}{l}\text { Time taken for sensory block to } \\
\text { reach T10 in mins }\end{array}$} & \multicolumn{2}{|c|}{ Group LF } & \multicolumn{2}{|c|}{ Group LN } & \multirow{2}{*}{$\begin{array}{c}P \\
\text { Value }\end{array}$} \\
\hline & Mean & SD & Mean & SD & \\
\hline & 4.73 & 0.5 & 5.81 & 0.49 & $<0.001$ \\
\hline $\begin{array}{l}\text { Time taken to achieve maximum } \\
\text { sensory blockade in mins }\end{array}$ & 6.31 & 0.56 & 8.16 & 0.47 & $<0.001$ \\
\hline Time for two segment regression & 102.13 & 8.220 & 103.03 & 11.64 & 0.731 \\
\hline Duration of analgesia & 300.67 & 33.185 & 332.33 & 35.32 & 0.001 \\
\hline Onset of motor blockade in mins & 3.25 & 0.38 & 4.89 & 0.41 & $<0.01$ \\
\hline $\begin{array}{l}\text { Time taken for maximum motor } \\
\text { blockade in min }\end{array}$ & 5.11 & 0.4 & 6.4 & 0.63 & $<0.01$ \\
\hline
\end{tabular}

Table 2 shows the mean time of onset of sensory block to T10 level and at highest sensory level, both of which was statistical significantly lower in group LF than group LN $(\mathrm{P}<$ 0.001). The difference in two segment sensory regression time in both groups were not significant $(\mathrm{P}=0.731)$. Analgesic duration was lesser in group LF than group LN and this difference was highly significant $(\mathrm{P}<0.01)$. Table 2 also shows the mean time of onset of motor block and time to reach maximum motor blockade, both was lesser in group LF than in group LN $(\mathrm{P}<0.01)$.

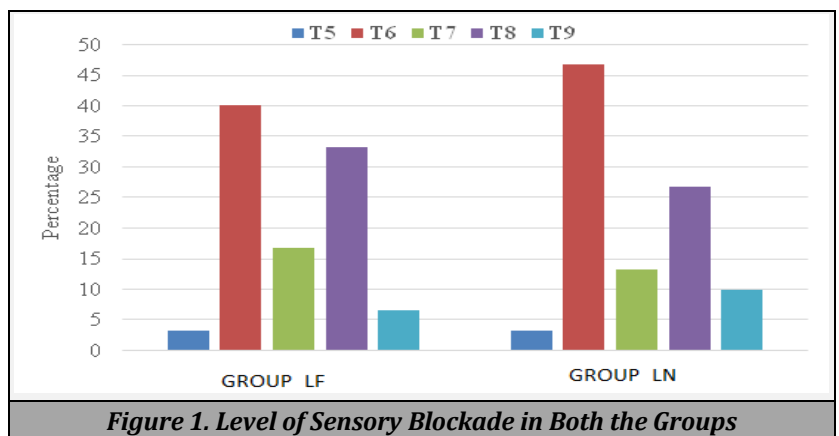

Majority of patients in both the groups achieved level T6. There was no statistically significant difference found between two groups with respect to maximum level of sensory blockade. $(\mathrm{P}$ value $=0.953)$

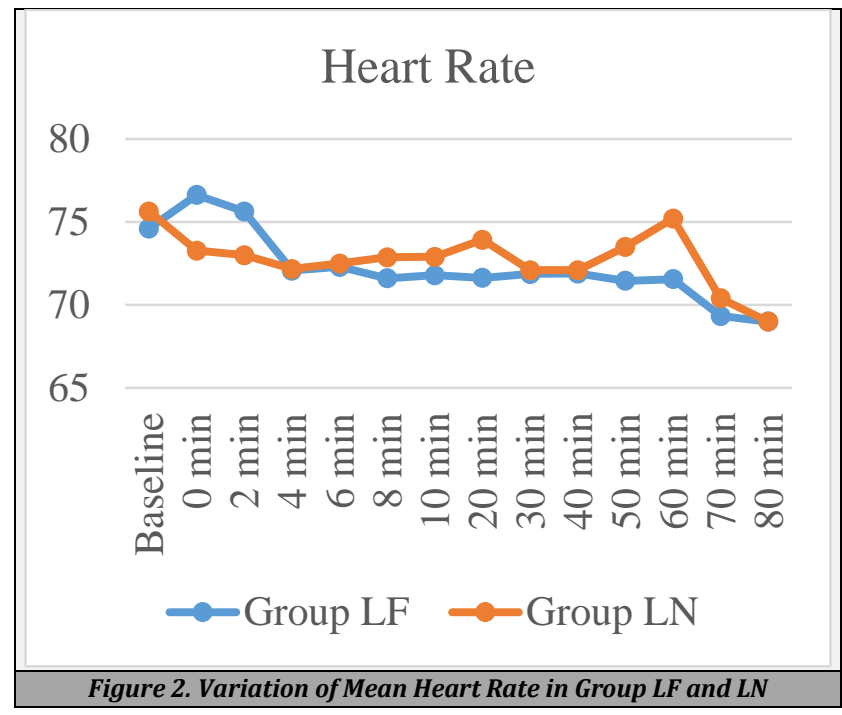

Figure 2 shows mean HR per minute at various time intervals in group LF and group LN. Mean HR had no significant difference between the two groups at different time intervals $(\mathrm{P}>0.05)$.

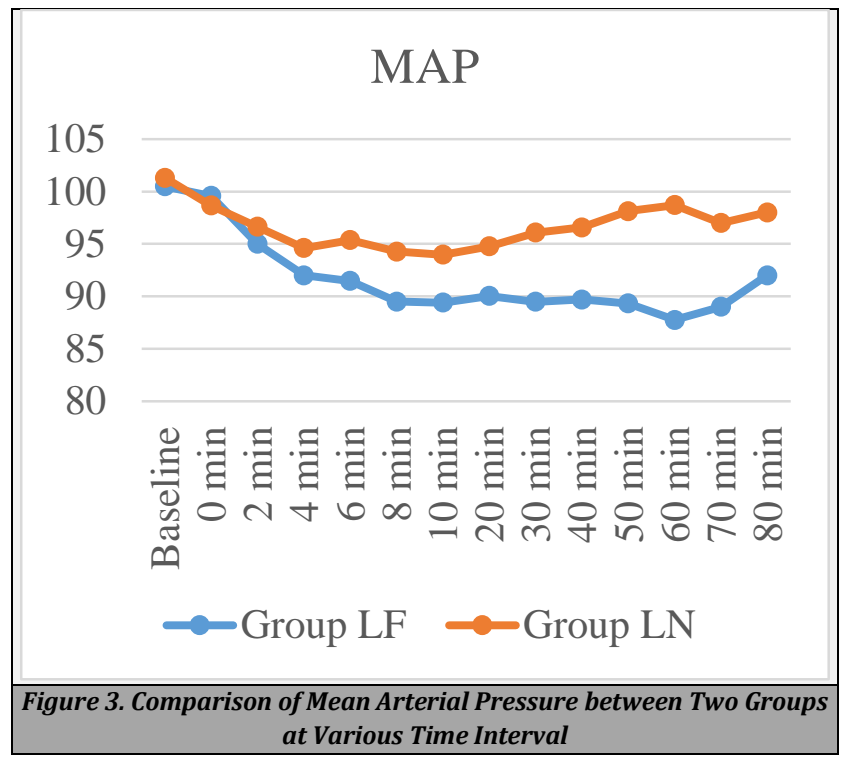

Figure 3 shows mean arterial blood pressure at various time intervals in Group LF and Group LN. Significant difference was observed in mean arterial pressures between the two groups at various intervals (20 - 60 mins).

\begin{tabular}{|cccc|}
\hline $\begin{array}{c}\text { Number of Patients with Side } \\
\text { Effects (\%) }\end{array}$ & $\begin{array}{c}\text { Group LF } \\
(\mathbf{n}=\mathbf{3 0})\end{array}$ & $\begin{array}{c}\text { Group LN (n } \\
\mathbf{=} \mathbf{3 0})\end{array}$ & $\begin{array}{c}\text { Total (n = } \\
\mathbf{6 0})\end{array}$ \\
Bradycardia & $1(3.3 \%)$ & $1(3.3 \%)$ & $2(3.3 \%)$ \\
Hypotension & $3(10 \%)$ & $2(6.7 \%)$ & $5(8.3 \%)$ \\
Shivering & $2(6.7 \%)$ & $3(10 \%)$ & $5(8.3 \%)$ \\
Pruritis & $2(6.7 \%)$ & $2(6.7 \%)$ & $4(6.7 \%)$ \\
Nil & $22(73.3 \%)$ & $22(73.3 \%)$ & $44(73.3 \%)$ \\
Nausea and vomiting & 0 & 0 & 0 \\
Total & $\mathbf{3 0}(\mathbf{1 0 0} \%)$ & $\mathbf{3 0}(\mathbf{1 0 0} \%)$ & $\mathbf{6 0}(\mathbf{1 0 0} \%)$ \\
\hline Table 3. Side Effects during Anaesthesia & \\
\hline \multicolumn{4}{|c}{}
\end{tabular}


Table 3 shows adverse effects in Group LF and Group LN which shows no statistically significant difference (P value 0.982).

\section{DISCUSSION}

During 1980s, to decrease adverse cardiac effects of bupivacaine, safer compounds were needed. As a result of these efforts, (S-) bupivacaine (levobupivacaine) has been recognized as the lesser cardiotoxic and lesser neurotoxic. ${ }^{12}$ Hence, because of reduced toxicity, it appears to be an attractive alternative to bupivacaine. ${ }^{13}$

Lee et al. deduced that the relative anaesthetic potency ratio for levobupivacaine/bupivacaine is 0.97 .14 Thus, levobupivacaine has similar efficacy but an enhanced safety profile compared to bupivacaine. McLeod in his classic investigation on the effect of temperature and addition of dextrose to local anaesthetic solutions, has shown that 5 $\mathrm{mg} / \mathrm{ml}$ of levobupivacaine can be considered to be isobaric at $23^{\circ} \mathrm{C}$ and $37^{\circ} \mathrm{C}$ in males and post-menopausal females according to the results of Lui and colleagues. ${ }^{6}$

Hyperbaric solutions have the risk of extension of early regression of the block. They may cause hypotension and bradycardia after mobilization which are less with use of truly isobaric solutions.

Thus, levobupivacaine being isobaric may be considered in specific patient groups, such as obstetric patients and extremes of ages.

Lee et al. performed the first clinical study investigating clinical efficacy of $2.6 \mathrm{ml} 0.5 \%$ levobupivacaine for spinal anaesthesia for urological surgery and found that it was an effective local anaesthetic. ${ }^{13}$

Dizman et al. evaluated spinal isobaric levobupivacaine on sensory and motor blockade in patients undergoing TURP surgeries and found that the minimum effective spinal isobaric levobupivacaine dose was $10 \mathrm{mg}^{15}$

The addition of lipophilic opioids as adjuvants intrathecally reduces block onset time of the block, improves of surgical anaesthesia quality and analgesia duration. These opioids have lesser rostral spread in sub arachnoid space compared to hydrophilic opioids and hence lesser chances of respiratory depression. ${ }^{16}$

Recently, nalbuphine has been added to the local anaesthetic agents as an adjuvant. Nalbuphine is an $\mu$ receptor antagonist and $\mathrm{K}$ receptor agonist with lower respiratory depression effect and abuse potential. ${ }^{17}$

Ben-David et al. and Cuvas et al. found that the addition of $10 \mu \mathrm{g}$ fentanyl to spinal anaesthesia with dilute small dose bupivacaine intensified the sensory blockade and its duration. ${ }^{18,19}$

Karsli et al. demonstrated that the ED95 of intrathecal isobaric levobupivacaine co administered with $25 \mu$ g fentanyl for TURP was $10.88 \mathrm{mg}^{20}$

Culebras et al. conducted study in caesarean section with three different doses of nalbuphine $0.2,0.8$ and $1.6 \mathrm{mg}$ with $0.5 \%$ hyperbaric bupivacaine and compared with morphine $0.2 \mathrm{mg}$ with bupivacaine. They reported that no differences were found with respect to maternal oxygen desaturation and APGAR (appearance, pulse, grimace, activity and respiration) scores. ${ }^{21}$
Jyothi et al. demonstrated that nalbuphine at doses 0.8 $\mathrm{mg}, 1.6 \mathrm{mg}$ and $2.4 \mathrm{mg}$ provides good quality and longer duration of post-operative analgesia. ${ }^{17}$

In our study, onset of sensory blockade is faster with fentanyl compared to nalbuphine which is statistically significant which is consistent with the results by most of the previous studies like, Prabhakaraiah et al. Naaz et al. who investigated these opioids in combination with hyperbaric bupivacaine. ${ }^{22,23}$

The time of onset of sensory analgesia with levobupivacaine fentanyl combination in our study correlates well with that obtained by Bindra et al. ${ }^{11}$ They used $10 \mathrm{mg}$ of hyperbaric bupivacaine with $20 \mu \mathrm{g}$ of fentanyl intrathecally for caesarean sections. The time onset of sensory analgesia of levobupivacaine nalbuphine combination correlates well with Rehab OM et al. who used combination of $7.5 \mathrm{mg}$ of levobupivacaine with $1 \mathrm{mg}$ of nalbuphine in TURP. ${ }^{24}$

As suggested by Akan et al. in TURP, the addition of opioids to intrathecal levobupivacaine hastens the onset of sensory analgesia and our values with levobupivacaine fentanyl and levobupivacaine nalbuphine combinations for motor blockade were superior to the results obtained by Fattorini et al. Vanna et al. Lee et al. and Cuvas et al. where isobaric levobupivacaine alone was used as intrathecally. ${ }^{25,26,12,13}$

In our study, the maximum sensory level obtained in group LF and group LN was T5 which was not statistically significant $(\mathrm{P}<0.953)$. The probable cause of achieving a lower dermatomal level was due to isobaric nature of levobupivacaine which is supported by the findings of Fattorini et al. ${ }^{26}$

Time for peak sensory level was achieved earlier in Group LF compared to Group LN which was statistically significant. This faster onset to a greater maximal dermatomal level of analgesia with fentanyl combination compared to nalbuphine is consistent with similar results obtained by Naaz et al. ${ }^{23}$ in lower limb orthopaedic surgeries, Bindra et al. ${ }^{17}$ in caesarean sections, Prabhakaraiah et al. ${ }^{22}$ in lower abdominal surgeries.

The difference in two segment sensory regression time in both groups was not statistically significant. The values for two segment sensory regression times with levobupivacaine fentanyl combination are similar to those obtained by Vanna et al. Cuvas et al. ${ }^{12,19}$

Using $12.5 \mathrm{mg}$ bupivacaine, Naaz et al. obtained a twosegment sensory regression time of $108 \pm 32.03$ min with fentanyl and $91.6 \pm 31.12$ min with nalbuphine which was statically insignificant and was comparable to our study. ${ }^{23}$

Duration of analgesia is defined as time from spinal injection to first rescue analgesia. The analgesic duration was statistically significantly longer in group LN compared to LF.

Akan et al. studied the addition of $25 \mu \mathrm{g}$ fentanyl to $7.5 \mathrm{mg}$ levobupivacaine produced a prolonged total duration of analgesia which is comparable to our results in the group LF. 25

Naaz et al. observed that duration of analgesia using bupivacaine with fentanyl was shorter than that of bupivacaine with nalbuphine with significant difference statistically. ${ }^{23}$ Gomaa et al. did not observe any significant difference between intrathecal fentanyl $25 \mu \mathrm{g}$ and nalbuphine $0.8 \mathrm{mg}$ when compared for post-operative analgesia. This is at variance from the findings of the present study, which showed a significant difference between the same. ${ }^{27}$ 
In our study, onset of motor block was faster in group LF than group LN. Prabhakaraiah et al. observed that time of onset of motor block was faster with bupivacaine fentanyl combination than bupivacaine nalbuphine combination. ${ }^{22}$ This faster onset of motor block compared to our study may be attributed to hyperbaric nature of bupivacaine.

Cuvas et al. observed that the addition of opioids produces a faster onset of motor block compared to isobaric levobupivacaine alone in TURP procedures, even though the local anaesthetic dose is reduced. ${ }^{19}$

In the present study, the average time to attend grade III/IV Bromage motor blockade was lower in group LF than in group LN. This faster achievement of maximum motor block with fentanyl is consistent with the studies by Prabhakaraiah et al. and Naaz et al. ${ }^{22,23}$

In both the groups, the HR remained stable and there was no significant intergroup difference. While 1 patient each in group LF and group LN showed bradycardia and needed a dose of atropine $0.6 \mathrm{mg}$. Results obtained in our study nearly matches with the study results of Naaz et al. Bindra et al. Gupta et al. and Prabhakaraiah et al. in populations of different patients. ${ }^{17,22,23,28}$ These side effects in both the groups did not require any intervention and were not statistically significant.

\section{CONCLUSIONS}

Intrathecal nalbuphine $0.8 \mathrm{mg}$ as an adjuvant to isobaric levobupivacaine $0.5 \% 10 \mathrm{mg}$ is as efficacious as fentanyl 25 $\mu \mathrm{g}$, as an adjuvant to isobaric levobupivacaine $0.5 \% 10 \mathrm{mg}$ in elderly patients undergoing urological endoscopic surgeries, with respect to the analgesia, motor block and hemodynamic parameters.

\section{Limitations of the Present Study}

In this study, the evaluation of intrathecal drugs was done in elderly patients undergoing TURP surgeries. With the possible presence of cardio-respiratory co morbidities, this patient population may show haemodynamic changes which may not be seen in younger patient populations. Sample size for present study being small $(n=30)$ in each group. Further studies with much larger sample may be needed to generalize the outcome to different sets of subjects. The long-term effects of nalbuphine as an intrathecal adjuvant is not evaluated in the present study. Transurethral endoscopic surgeries being less painful than open surgeries extension of same dose of drugs in open surgeries may not be adequate, for which further studies are needed.

Data sharing statement provided by the authors is available with the full text of this article at jemds.com.

Financial or other competing interests: None.

Disclosure forms provided by the authors are available with the full text of this article at jemds.com.

\section{REFERENCES}

[1] Malhotra V, Sudheendra V, O'Hara J, et al. Anesthesia and the renal and genitourinary systems. Miller's
Anaesthesia. $7^{\text {th }}$ edn. Elsevier/ Churchill Livingstone 2010.

[2] Pollock JE, Mulroy MF, Bent E, et al. A comparison of two regional anesthetic techniques for outpatient knee arthroscopy. Anesth Analg 2003;97(2):397-401.

[3] Kararmaz A, Kaya S, Turhanoglu S, et al. Low dose bupivacaine fentanyl spinal anaesthesia for transurethral prostatectomy. Anaesthesia 2003;58(6):526-30.

[4] Kuusniemi KS, Pihlajamaki KK, Pitkanen MT, et al. The use of bupivacaine and fentanyl for spinal anaesthesia for urological surgery. Anesth Analg 2000;91(6):1452-6.

[5] Gupta S, Sampley S, Kathuria S, et al. Intrathecal sufentanil or fentanyl as adjuvants to low dose bupivacaine in endoscopic urological procedures. Journal of Anaesthesiol Clin Pharmacol 2013;29(4):50915.

[6] McLeod GA, Burke D. Levobupivacaine. Anesthesia 2001;56(4):331-41.

[7] MacKenzie TA, Young ER. Local anesthetic update. Anesth Prog 1993;40(2):29-34.

[8] Morrison SG, Dominguez JJ, Frascarolo P, et al. A comparison of the electrocardiographic cardiotoxic effects of racemic bupivacaine, levobupivacaine and ropivacaine in anesthetized swine. Anesth Analg 2000;90(6):1308-14.

[9] Greene NM. Distribution of local anesthetic solutions within the subarachnoid space. Anesth Analg 1985;64(7):715-30.

[10] Schmauss C, Doherty C, Yaksh TL. The analgesic effects of an intrathecally administered partial opiate agonist, nalbuphine hydrochloride. Eur J Pharmacol 1982;86(1):1-7.

[11] Bindra TK, Kumar P, Jindal G. Post-operative analgesia with intrathecal nalbuphine versus intrathecal fentanyl in cesarean section: Anesth Essays Res 2018;12(2):5615.

[12] Vanna O, Chumsang L, Thongmee S. Levobupivacaine and bupivacaine in spinal anaesthesia for transurethral endoscopic surgery. J Med Asoc Thai 2006;89(8):1133-9.

[13] Lee YY, Muchhal K, Chan CK. Levobupivacaine versus racemic bupivacaine in spinal anaesthesia for urological surgery. Anaesth Intensive Care 2003;31(6):637-41.

[14] Lee YY, Kee WDN, Fong SY, et al. The median effective dose of bupivacaine, levobupivacaine and ropivacaine after intrathecal injection in lower limb surgery. Anesth Analg 2009;109(4):1331-4.

[15] Dizman S, Turker G, Gurbet A, et al. Comparison of two different doses of intrathecal levobupivacaine transurethral endoscopic surgery. Eurasian J Med 2011;43(2):103-8.

[16] Ade BF, Braga FS, Poterio GM, et al. Sufentanil added to hyperbaric bupivacaine for subarachnoid block in ceaserean section. Eur J Anaesthesiol 2003;20(8):631-5.

[17] Jyothi B, Gowda S, Shaikh SI. A comparison of analgesic effect of different doses of intrathecal nalbuphine hydrochloride with bupivacaine and bupivacaine alone for lower abdominal and orthopedic surgeries. Indian J Pain 2014;28(1):18-23.

[18] Ben-David B, Solomon E, Levin H, et al. Intrathecal fentanyl with small-dose dilute bupivacaine: better 
anesthesia without prolonging recovery. Anesth Analg 1997;85(3):560-5.

[19] Cuvas O, Basar H, Yeygel A, et al. Spinal anesthesia for transurethral resection operations: Levobupivacaine with or without fentanyl. Middle East J Anesthesiol 2010;20(4):547-52.

[20] Karsli ND, Subasi D, Terzioglu B, et al. ED90 and ED95 of intrathecal isobaric levobupivacaine co-administered with fentanyl for transurethral resections: randomized, double-blind trial. Drug Res (Stuttg) 2015;65(1):24-9.

[21] Culebras X, Gaggero G, Zatloukal J, et al. Advantages of intrathecal nalbuphine compared with intrathecalmorphine, after cesarean delivery: an evaluation of postoperative analgesia and adverse effects. Anesth Analg 2000;91(3):601-5.

[22] Prabhakaraiah UN, Narayanappa AB, Gurulingaswamy S, et al. Comparison of nalbuphine hydrochloride and fentanyl as an adjuvant to bupivacaine for spinal anaesthesia in lower abdominal surgeries. A randomized, double-blind study. Anesth Essays Res 2017;11(4):859-63.

[23] Naaz S, Shukla U, Srivastava S, et al. A comparative study of analgesic effect of intrathecal nalbuphine and fentanyl as adjuvant in lower limb orthopedic surgery. J Clin Diagn Res 2017;11(7):UC25-UC8.
[24] Rehab OM, AI Shreif SI, Amr YM, et al. Different low doses of levobupivacaine $0.5 \%$ with nalbuphine in spinal anaesthesia for transurethreal resection of prostate surgery. Tanta Med J 2017;45(2):57-63.

[25] Akan B, Yagan O, Bilall B, et al. Comparison of levobupivacaine alone and in combination with fentanyl and sufentanil in patients undergoing transurethral resection of the prostate. J Res Med Sci 2013;18(5):37882.

[26] Fattorini F, Ricci Z, Rocco A, et al. Levobupivacaine versus racemic bupivacaine for spinal anaesthesia in orthopaedic major surgery. Minerva Anestesiol 2006;72(7-8):637-44.

[27] Gomaa HM, Mohamed NN, Zoheir HA, et al. A comparison between post-operative analgesia after intrathecal nalbuphine with bupivacaine and intrathecal fentanyl with bupivacaine after caesarean section. Egypt J Anaesth 2014;30(4):405-10.

[28] Gupta K, Rastogi B, Gupta PK, et al. Intrathecal nalbuphine versus intrathecal fentanyl as adjuvant to $0.5 \%$ hyperbaric bupivacaine for orthopedic surgery of lower limbs under subarachnoid block: a comparative evaluation. Indian J Pain 2016;30(2):90-5. 